\title{
Food Waste and Loss of Weight in Cooking
}

\author{
By Gweneth M. Chappell \\ Household Arts Department, Queen Elizabeth College, University of London
}

(Received 18 March 1954)

There is a dearth of information on the percentage of waste during preparation of food by the average woman. Such figures would be of value in dietary surveys, since some food tables give analyses for raw foods only 'as purchased', so that edible portions on dietary records must often be converted to 'as purchased' amounts before conversion to calories and nutrients.

During two long-term dietary investigations, records of wastage in food preparation were made and results are presented for comparison with existing tables or as a supplement to them.

In addition, alterations in weight during cooking are of great importance when the nutritive value of edible portions of food is to be calculated. Alterations are chiefly due to loss or absorption of water or other liquid and also to loss of weight when fat melts and connective tissue hydrolyses to gelatin. Outer layers of old potato may slough away and fish may break apart.

\section{EXPERIMENTAL}

General. Loss or gain of weight during cooking has an effect on the nutritive value of a given weight of cooked food. As an example, two rice puddings consumed during the survey are cited. Both were made to the same recipe, but one lost $3.4 \%$ and the other $49 \%$ of its original weight: the first was cooked alone in a slow oven and the second was placed below other foods in a moderately hot oven.

Recipe: $568 \mathrm{~g}$ milk, $57 \mathrm{~g}$ sugar, $42 \mathrm{~g}$ rice, $\mathrm{I} 4 \mathrm{~g}$ butter. Total weight $68 \mathrm{I} \mathrm{g}$.

Pudding I. $3 \cdot 4 \%$ loss of weight. Portion consumed $142 \mathrm{~g}$. Foods contained in this portion: $122 \mathrm{~g}$ milk, $12.3 \mathrm{~g}$ sugar, $9.0 \mathrm{~g}$ rice, $3.0 \mathrm{~g}$ butter.

Pudding 2. $49 \%$ loss of weight. Portion consumed $142 \mathrm{~g}$. Foods contained in this portion: $233 \mathrm{~g}$ milk, $23.8 \mathrm{~g}$ sugar, $17.6 \mathrm{~g}$ rice, $5.8 \mathrm{~g}$ butter.

Unless allowance is made for evaporation during cooking, there is thus likely to be great inaccuracy in calculating the nutrient content of composite dishes. To avoid this error, each dish cooked during the survey was made with weighed ingredients and the whole was weighed before and after cooking. Weighing a raw mixture allowed a correction to be made for any part of the whole adhering to the mixing bowl.

Scope of the survey. Results in the present investigation cover the years 1949-52, and the average value for all figures computed in these years is given for each commodity. Care was taken to ensure that all edible parts were utilized, although, unfortunately, such care is not always practised by the average woman.

The number of samples of each food used to give a mean value varied from 12 to over 200. Many results varied widely from the mean for that food, especially those 
for wastage of vegetables, where samples of varying quality were used. Additional figures for wastage in the preparation of some vegetables, of fish and of rich cakes were obtained from students training at Queen Elizabeth College.

Methods. Ingredients of cooked dishes, waste material and many raw foods were weighed on a dietary scale reading to $\mathrm{I} g$. Poultry, joints of meat and whole fish were weighed on counterpoise scales (tested by W. and T. Avery Ltd., Birmingham) weighing to $\frac{1}{4} \mathrm{oz}$. Counterpoise scales were also used for whole cooked dishes.

Vegetables were boiled in a small volume of salted water and bicarbonate of soda was not added to the cooking water. Cabbage was shredded immediately before boiling, and cooking was ended when leafy vegetables were still slightly firm. Root vegetables were boiled until completely tender. Leafy vegetables were thoroughly drained in a colander, but excessive pressure to remove water was avoided where it would not normally be used by the housewife. Vegetables were not drained indefinitely, since they would have become too cold to be palatable.

Fried and roast foods were weighed on absorbent paper, which was then weighed alone in order that allowance could be made for any fat adhering to it.

\section{RESULTS AND DISCUSSION}

Mean values are given for foods of similar kind, e.g. rich cakes, yeast mixtures and milk moulds, although each sample within a group was not necessarily made to the same recipe.

Comparison with earlier studies cannot legitimately be made because change of weight in cooking is influenced by many factors such as recipes, consistencies, ingredients, cooking times and temperatures, and volume of cooking liquid; the results are also influenced by rate of boiling, i.e. whether the water is fast boiling or barely bubbling, and by the composition, thickness and surface area of samples of raw food.

No attempt at precise standardization of consecutive cookings was made in the present investigation, since the work was undertaken to show changes occurring in normal careful domestic cookery.

For these reasons, results are not compared critically with experimental findings in earlier studies, but it is interesting to see how closely many of the present values agree with earlier ones.

\section{Loss of weight on cooking}

In Table I, change of weight in cooking is expressed as a percentage of the raw, edible weight.

Cakes, pastry, puddings, biscuits and scones

The greatest loss in weight in rich cake mixtures occurred, as in omelets, when egg white was beaten until stiff and folded into the prepared mixture. No doubt this was due to the fact that only small cakes were prepared by this souffle method, so that evaporation was proportionately greater than that from one large cake. Lowe (1944) reports that no moisture was lost by evaporation from any portion of an angel cake farther from the outer edge than $\mathrm{I} \mathrm{cm}$.

Small pieces of scones, pastry and yeast mixtures all lost more weight than large ones, and weight loss increased as the amount of moisture in the recipe increased, 
Table r. Percentage change of weight of foods during cooking, expressed as a percentage of the raw, edible weight

\section{Change in weight}

Food

No. of samples
Baked puddings

Biscuits : plain

rich

Custard powder sauce

Cakes: rich

plain and gingerbread

sponge and genoese

American recipes

Coconut pyramids

All cakes

All cakes except meringues and pyramids (see eggs)

Forcemeat, baked

Macaroons

Milk puddings:

baked whole grain

moulds fine grain

Macaroni, boiled

Pancakes

Pastry: choux

Rice, boiled puff and flaky

Shortbread

Scones

Sage and onion stuffing

Steamed puddings

Tarts, open and covered

Yeast baking

Yeast girdle cookery

Yorkshire pudding

Bread : fried toasted

Buns and crumpets, toasted

Baked soufflés

Meringues and jap cakes

Custard, baked, shell egg

Omelets

Sebayon and egg sauces
2 I

17

I5

88

II 5

57

22

14

14

208

15

18

I 2

I 2

13

16

12

21
3.3 to -9.7
$-\quad 1.7$ to -9.5

$-5 \cdot 1 \pm 0.46$

$-5 \cdot 6 \pm 0.83$

Mean value with its standard error

$-9.4 \pm 0.91$

$-9.2 \pm 0.87$

$-4.5 \pm 0.31$

- 9.1 \pm 0.28

$-10.1 \pm 0.31$

- 5.1 to -26.0

$-14 \cdot 2 \pm 1.05$

$-10.5 \pm 0.81$

- 2.4 to - IS.3

- 2.0 to -54.0

- 2.0 to -26.0

-2.0 to -39.2

$-7.1 \pm 1.0$

$-11 \cdot 0 \pm 0.4$

$-10.0 \pm 0.24$

$-19.6 \pm 277$

-4.0 to -19.4

$-10 \cdot 6 \pm I \cdot 18$

-3.4 to -48.9

$-19.4 \pm 2.03$

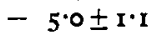

$+198 \pm 5.49$

+168 to +230

$-13.0 \pm 0.95$

$-40 \cdot 3 \pm I \cdot 3$

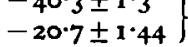

$+222 \pm 7 \cdot 21$

$-7 \cdot 5 \pm I \cdot 02$

$-I 4 \cdot 2 \pm I \cdot I 4$

$-21 \cdot 7 \pm 2 \cdot 85$

$+0.4 \pm 1.04$

$-6.6 \pm 0.6$

- I I.8 \pm I.29

$-24 \cdot 3 \pm 1 \cdot 99$

$+3 I \cdot 7 \pm 2 \cdot 5$

$-13 \cdot 3 \pm 0.77$

$$
\text { o to }-13.6 \quad-5.4 \pm 1.03
$$

$$
\text { Eggs }
$$

- $7 \cdot 3$ to -13.1

$-10.1 \pm 0.49$

$-34 \cdot 9 \pm 2 \cdot 2$

-3.1 to $-10.6 \quad-8.3 \pm 1.27$
$-12 \cdot 8 \pm 0.60$

$-7 \cdot 6 \pm \mathrm{I} \cdot 77$
Cake mixtures and charlottes, no pastry or milk puddings

Less than half fat to

flour in recipe

More than half fat to flour

More than half fat to flour in recipe

Soft batter, well beaten before cooking

Breadcrumb base. Smallest loss when covered tin was used

Chiefly rice puddings

Chiefiy cornflour

Baked blind

$-2.0 \%$ when cooked in covered tin

Stale bread lost less weight than new bread

$$
\begin{aligned}
& -27 \text { to }-36 \% \text { fresh } \\
& \text { egg, }-48 \text { to }-54 \% \\
& \text { dried egg }
\end{aligned}
$$

Plain omelets $-\mathrm{I} \cdot 7$ to $5.7 \%$, soufflé omelets -2.3 to $-9.5 \%$

Larger losses occurred with slow cooking 
Table I (cont.)

Change in weight

Food $\begin{gathered}\text { No. of } \\ \text { samples }\end{gathered}$

Food
Baked
Fried
Grilled
Poached
Steamed
Fish cakes and puddings
Apple, baked
Stewed fruit and syrup
Banana
$\begin{aligned} & \text { Figs } \\ & \text { Pineapple } \\ & \text { Prunes }\end{aligned}$, $\begin{aligned} & \text { stewed or } \\ & \text { soaked until } \\ & \text { added }\end{aligned}$

Bacon, fried or baked

Steak, fried

Chop, grilled

Roast

Stewed

Ham, boiled

Poultry, roast

Cheese

Onion

White

Various

Asparagus, boiled

Broad beans, boiled

Brussels sprouts, boiled

Cauliflower, sprigged,

boiled

Chicory, boiled

-4.4 to -38.0

15
60
15
14
12

-6.6 to -33.3

0 to -20.0

-5.4 to -16.0

0 to $-18.0 \quad-6.2 \pm 1.47$

\section{Fruit}

$-I \cdot 3$ to $-3^{6 \cdot 3} \quad-17 \cdot 1 \pm 2 \cdot 92$

$$
0 \text { to }-30.7-9.4 \pm 1.09
$$

Fruit (dried)

+35.6 to $+128.1+90.7 \pm 8.58$
+23.3 to $+49.8+35.9 \pm 2.53$
+123.8 to $+259.0+190.7 \pm 10.18$

+123.8 to $+259.0+190.7 \pm 10.18$
+21.6 to $+100.0+64.1 \pm 5.84$

\section{Meat}

-22.0 to $-72.8 \quad-53.0 \pm I \cdot 39$

$-18 \cdot 4$ to $-44 \cdot 3$

$-29 \cdot 4 \pm I \cdot 62$

$-21 \cdot 4$ to $-46 \cdot 4 \quad-3 I \cdot 8 \pm x \cdot 84$

$-10 \cdot 0$ to $-24 \cdot 1 \quad-15 \cdot 4 \pm 1 \cdot 26$

$-7 \cdot 1$ to $-33 \cdot 1 \quad-22 \cdot 8 \pm 2 \cdot 34$

Sauces
o to -13.5
$-5 \cdot 4 \pm I \cdot 39$
$-5 \cdot 1 \pm 1 \cdot 2$

0 to -19.3

Soups

Vegetables

$-12 \cdot 0$ to +4.5

$-12 \cdot 3$ to $+3 \cdot 6$

$-0.5 \pm 1.03$

$-2 \cdot 7 \pm 1.06$

$$
-15.6 \text { to }+8.2 \quad-2.5 \pm 0.7
$$

Mean value with its standard error

\section{Fish}

-12.9 to $-49 \cdot 4 \quad-32 \cdot 3 \pm 2.04$

-12.6 to $-39.3 \quad-26.4 \pm 1.05$

1950: larger losses and no gain. 1952: small loss or gain

Gains only (no losses) February to May. Losses only (no gains) September to January Loss or gain in same batch cooked on same day

Includes plaice, turbot, sole, halibut, whitebait, salmon, cod and bream. Fried with egg and breadcrumb or milk and flour coating. No batter used

Higher values for puddings (containing milk)

$-\mathrm{I} \cdot 3 \%$ when cooked in covered dish

Greatest increase given with prolonged stewing

Values similar for either method of cooking

Beef, pork, mutton and veal

Beef (nine samples)

$-21 \cdot 4$ to $-36 \cdot 7$.

Mutton (nine samples)

$-2 \mathrm{I} \cdot 4$ to -46.4

Includes game, whole birds cooked

Includes loss due to evaporation 
Table I (cont.)

Change in weight

Food

No. of samples

Corn-on-the-cob, boiled

Cabbage, boiled

Carrot, old, boiled

Jerusalem artichoke,

boiled

Leek, boiled

Marrow, boiled

Mushroom: fried stewed

Peas : garden, boiled

frozen, boiled

Parsnip : boiled

roast

Potato: new, boiled

old, boiled

old and new

baked in stock

chips

roast

boiled and then

fried

Onion: baked in stock

boiled

fried

Runner beans, boiled

Seakale, boiled

Spinach : boiled

$$
\text { boiled and }
$$
sieved

Spring greens, boiled

Swede : boiled

pressure cooked

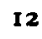

28

27

13

18

13

14

12

2 I

12

12

12

22

35

57

I 2

16

12

12

I6

14

12

16

19

19

I 2

41

I 4

18
-1.8 to -18.8

$-10 \cdot 8 \pm 1 \cdot 65$

$-11 \cdot 8$ to $+11 \cdot 1$

$-0.3 \pm 1 \cdot 98$

-19.4 to -50.0

$-3 r \cdot 6 \pm 2 \cdot 60$

-7.4 to $+8.0 \quad-1.2 \pm 0.59$

-9.1 to $+10.4 \quad+0.04 \pm 0.78$

-9.1 to +10.4

$-0.45 \pm 0.53$

$-17 \cdot 1$ to +0.5

$-9.5 \pm 1.77$

Largest gains when cob barely ripe or at end of season

Five gains, all in August or November

Three gains in 3 years, all in August or September

One gain in August 1949 and one in August r952, losses in same month. Losses over $10 \%$ in June and August

Loss depends partly on amount of ice adhering to peas

Gain at beginning of season only

One gain in May, one in June, several in August Often $5 \%$ or more loss or gain if broken to flour

Largest loss in potatoes partly in air, smallest loss in those submerged in stock

See potato baked in stock

Absorbed approximately 1 $2 \%$ of its own raw weight of frying fat

No change of weight, or less than $x \%$ in three cookings

Loss or gain at any time and often on same day

Cooked in thin slices in boiled salted water Cooked in thin slices at I $5 \mathrm{lb}$. pressure for $7 \mathrm{~min}$ 
Table I (cont.)

\begin{tabular}{|c|c|c|c|c|}
\hline \multirow[b]{2}{*}{ Food } & \multirow[b]{2}{*}{$\begin{array}{c}\text { No. of } \\
\text { samples }\end{array}$} & \multicolumn{2}{|c|}{ Change in weight } & \multirow[b]{2}{*}{ Remarks } \\
\hline & & Range & $\begin{array}{l}\text { Mean value with } \\
\text { its standard error }\end{array}$ & \\
\hline & & \multicolumn{2}{|c|}{ Vegetables (cont.) } & \\
\hline Tomato: baked & 12 & -5.0 to -17.2 & $-8 \cdot z \pm 1 \cdot 04$ & \\
\hline fried & 15 & -6.0 to -43.4 & $-24 \cdot 7 \pm 2.95$ & \\
\hline grilled & 12 & 0 to -20.7 & $-11 \cdot 9 \pm x \cdot 75$ & $\begin{array}{l}\text { Whole tomatoes with } \\
\text { skin on did not lose } \\
\text { weight }\end{array}$ \\
\hline Turnip, boiled & 13 & $-19^{\circ} 4$ to $+21 \cdot 3$ & $-10 \cdot 4 \pm r \cdot 82$ & $\begin{array}{l}\text { Loss was greater if } \\
\text { vegetable was diced } \\
\text { before cooking }\end{array}$ \\
\hline
\end{tabular}

e.g. in crumpets, muffins, pancakes and scones. Thin pancakes and baked scones and pieces of pastry lost more weight than thicker ones.

The moisture content of the fat used for making pastry and shortbread influenced weight change. Pastry margarine (m.p. $64^{\circ}$ ) enables a wetter pastry dough to be used and increases weight loss. A large surface area and longer baking time increased the loss.

American recipes call for soft batters which are well beaten before cooking. Beating may result in the hydration of gluten and starch, with the result that weight loss in these cakes was no more than in English recipes.

When reconstituted dried egg albumen was used to make meringues, and reconstituted whole dried egg to make cakes and puddings, evaporation was much greater. It is suggested that the partial denaturation of protein by heat during the drying process prevents the absorption of some of the water used for reconstitution, leaving free moisture in the mixture. Whole dried egg does not go into colloidal solution for some hours after reconstitution, but owing to the danger of bacterial activity it is unusual to allow this length of time to elapse before using egg. Egg-white foams made from dried albumen are more tender than those made from fresh eggs, as they allow rapid leakage to occur during cooking.

Gain of weight in steamed puddings must have been due to absorption of water. Prolonged contact with steam sometimes allows permeation of moisture through greased greaseproof paper. Pressure cookers were used for some puddings and both gains and losses occurred in pressure cookery.

\section{Eggs}

Andross (1940) records a loss of $\mathrm{I} g$ for every $127 \mathrm{~g}$ of omelet mixture in recipes including $10 \mathrm{ml}$. water/egg. Values obtained in the present study were larger than this, but at least $20 \mathrm{ml}$. milk or water were added to every egg, and savoury omelets contained margarine as well.

Sebayon and egg-custard sauces showed the largest losses (up to $10 \cdot 6 \%$ ) with long, slow heating. With a high flame, weight loss ranged from $3 \cdot 1$ to $6.6 \%$.

Increasing the proportion of egg in baked custards lowered the coagulation temperature and resulted in a smaller loss of weight. A small surface area and a covered pie dish also reduced the loss. 
Values for fried egg are not included in Table $\mathrm{I}$, since careful cookery did not cause a change in weight. With fat at a very high temperature the white became burned and small pieces of albumen broke away from the whole, leading to as much as $14 \%$ loss in weight. Andross (1940) reports similar findings.

Meat

When heat is applied to raw meat, weight is lost because fat melts and shrinkage occurs, producing a slow contraction in volume which results in the rupture of cell walls and the exudation of water and soluble constituents. In nearly all methods of cookery water is constantly lost by evaporation. The greater the surface area of a piece of meat of given weight, the greater the rate of loss during cooking. Small cubes of meat lose weight and nutrients more quickly than large pieces and loss of weight increases with increased cooking time. In general, a high cooking temperature results in a large weight loss because the extent and rate of shrinkage are increased at high temperatures and evaporation proceeds rapidly in hot air, rising to $70-80 \%$ of the total water content by the time cooking is complete (McCance \& Shipp, 1933).

The quality, composition and degree of ripening of meat, the proportion of fat and bone, the shape, size and weight of a joint, the initial and final oven temperatures and the use of fresh or frozen meat all influence the final weight after cooking. It can be seen that the extent of possible errors in the values given in food tables is considerable and that personal taste partly determines the weight of a cooked joint since well-done meat cannot lose less than a certain proportion of its original weight. Thus, Lowe (1944) cooked paired two-rib beef roasts at $150^{\circ}$ and recorded an average loss of $7.7 \%$ in weight when the meat was rare (internal temperature $55^{\circ}$ ) and $16.6 \%$ when well done $\left(75^{\circ}\right)$.

Roasting. Andross (1946) cooked to an internal temperature of $77^{\circ}$. Mean values for roast joints in her studies (Andross, 194I, 1946) gave $27.8 \%$ loss of weight in mutton and $32.4 \%$ in beef. No thermometer was used in the present study, but all joints of mutton were well done and the mean weight loss was $28.3 \%$. On the other hand, beef was cooked until rare, medium or well done according to the taste of the consumer, resulting in a mean loss of $22.3 \%$. In order that comparison should be more just, all the values given by Andross for British and imported cuts have been averaged before comparing them with the present ones which were obtained with meat from both sources. Table 2 gives comparable mean values for loss from game and poultry.

Table 2. Loss of weight from roasting game and poultry

$\begin{array}{lcccc} & \text { Present study } & \text { Andross (I94r) } & \begin{array}{c}\text { McCance \& } \\ \text { Shipp (1933) }\end{array} & \text { Lowe (I944) } \\ \text { Chicken } & (\%) & (\%) & (\%) & (\%) \\ \text { Duck } & 16 \cdot 9 & 17 \cdot 0 & 26 \cdot 0 & 14 \cdot 5-18 \cdot 6 \text { for } \\ \text { Pheasant } & 33 \cdot 0 & - & 22 \cdot 0 & \text { halves of } \\ & 26 \cdot 4 & - & 29 \cdot 0 & \text { roasting chickens }\end{array}$

It is suggested that the large value of $33.0 \%$ for duck was due to the fat content.

Stewing. Stewing meat was denuded of almost all fat, cut into cubes of about 30-50 $\mathrm{g}$ weight and placed in hot water in a casserole which was left in a slow oven for 
$3 \mathrm{~h}$ or more. Loss of weight varied between $2 \mathrm{r} \cdot 4$ and $46.0 \%$ with an average of $31.8 \%$. The lower values may have been due to the presence of a solution of gelatin in interfibrillar spaces. The average loss from mutton was $32.3 \%$ and from beef $3 \mathrm{r} \cdot 3 \%$. These values are quite close to those recorded by McCance \& Shipp (1933, p. 46), obtained by applying factors $F_{1}$ and $F_{2}$ according to the formula given. They recorded a loss of $33 \%$ when pieces of steak, $2 \times 2 \times 0.5$ in., were stewed for $4 \mathrm{~h}$ and of $39 \%$ when scrag and neck of mutton were stewed. It is not clear whether fat was removed from mutton before stewing.

\section{Fish}

Fish muscle shrinks more slowly and less completely than meat muscle. Loss of weight is continuous and approximately $95 \%$ of the total loss is water. The loss of weight in frying is partly obscured by absorption of fat.

Throughout the present study it appeared that the attention given to fish during cooking and the avoidance of overcooking were the chief factors in preventing excessive loss of weight. A short time of unnecessary contact with heat can cause a greatly increased loss of weight.

Steaming and boiling. Although McCance \& Shipp (1933) report that portions of the same fish cooked by boiling, steaming and frying showed decreasing loss of weight in that order, loss in boiling is frequently less than in steaming because boiled fish retains water or a solution of gelatin between muscle flakes.

In the present investigation fish, other than thick cuts of cod, was steamed between two plates with milk and margarine on the lower one. Liquid from such fish could not drain away so readily as when fish is laid on the base of a perforated steamer or suspended in muslin. The mean loss from fish steamed between plates was $6.5 \%$ and that from cod suspended in muslin was $13.7 \%(12 \cdot 0-16 \cdot 0 \%)$. The additional loss cannot be attributed entirely to longer cooking time because turbot, cooked between two plates, required a longer time than cod in muslin and lost only $5 \cdot 7-6 \cdot 0 \%$ of its weight. It should be remembered, however, that cod muscle contains more water than turbot muscle.

McCance \& Shipp (1933) report a loss of $9 \%$ from plaice and $15 \%$ from turbot. Andross (194I) records a loss of $42.8 \%$ from cod and whiting. Comparable results in this study were $6 \cdot 7,5.9$ and $13.7 \%$. Some of the higher values in earlier studies may have been due to overcooking.

In the present study, fish was poached and not boiled because the movement of boiling water causes small particles of flesh to separate from the whole by mechanical disintegration. Acidulated water was used to hasten coagulation of protein, to inhibit shrinkage of muscle and hence to reduce weight loss. The methods used may account for the close agreement between mean values for poaching and steaming in this survey: poached fish lost $9.2 \%$ and steamed fish $9.5 \%$ of its weight. Each sample of cooked fish was well drained before weighing.

Frying, grilling and baking. There was no significant reduction in weight loss when a coagulable coating of egg and breadcrumb, or a mixture of flour and milk which gelatinizes on heating, was used for fish fried in deep or shallow fat. 
The average losses in weight from deep- and shallow-fried fish and from baked and grilled fish were within $2 \%$ of the mean results given by Andross (194I). In the present study these values were higher than those from steamed and poached fish, owing undoubtedly to the rapid evaporation occurring in dry heat.

Fish cakes, made by mixing cooked fish with cooked potato, were fried in shallow fat and showed losses of $0.7-6 \%$. Fish croquettes, made by mixing cooked fish with panada, were fried in deep fat and lost from $1 \cdot 7$ to $2 \cdot 8 \%$ of their weight.

\section{Bacon}

The average loss of $53.0 \%$ of weight from fried and baked rashers in the present study agreed closely with the loss of $54.0 \%$ recorded by McCance \& Shipp (1933), but individual losses of up to $\mathbf{7 2} \cdot \mathbf{8} \%$ were obtained when bacon contained a high proportion of fat.

\section{Vegetables}

McCance, Widdowson \& Shackleton (1936) attribute gain of weight during boiling and steaming to hydration, and loss of weight to the collapse of ligno-cellulose walls and the extrusion of juices contained within them and to shrinkage or to diffusion from dead cells. Hydration is most marked at temperatures between $80^{\circ}$ and $100^{\circ}$ and the collapse of cell walls at $120^{\circ}$, when pressure is applied. Two opposing forces are probably at work at all temperatures, but gain of weight probably occurs in the first few minutes.

Simpson \& Halliday (I94I) state that moist heat causes the partial breakdown of cellulose and pectic substances. They consider that cellulose may be liberated or partially hydrolysed. Though it does not seem likely that cellulose is hydrolysed in the conditions obtaining during boiling and steaming of vegetables, it is probable that other intercellular substances undergo hydrolysis or dissociation. As a result, cellulose is liberated, parts of the structural material split off the whole and vegetables lose weight. Loss of weight is generally proportional to cooking time. Small pieces lose weight more quickly than larger ones because a large surface is exposed to the leaching action of cooking water, structural cell material may be liberated by immediate contact with boiling water and evaporation is rapid in a dry medium. There is no evidence that the degree of shrinkage is affected by size.

Roasting and frying. Loss of weight during roasting and frying is due to evaporation of water, and the fat absorbed is insufficient to reduce this loss. McCance et al. (1936) record a loss of $43 \%$ in chipped potatoes after $6 \mathrm{~min}$ frying. The average loss in the present study was $42.4 \%$. For roast potatoes the mean values did not agree well, McCance et al. (1936) recording a loss of over $30 \%$ in $\mathrm{I} \mathrm{h}$, whereas the average in the present study was $19.2 \%$.

Boiling. Vegetables sometimes lost weight in boiling but there was often a gain. With some vegetables it appeared to be seasonal, e.g. cauliflower gained from February to May and lost from September to January, whereas parsnip gained weight only at the beginning of the season. This may be due to the short cooking time required for young vegetables, with the result that hydration occurred, but cooking was not continued long enough to cause loss of weight due to the collapse of cell walls. 
With leafy vegetables gain of weight was undoubtedly due to water enclosed between lamellae, e.g. in brussels sprouts, leeks and spinach. An almost continuous seepage occurred from leeks, marrow and spinach, and careful draining in a colander did not remove all surplus water.

The same vegetable cooked in the same way on different occasions sometimes gained and sometimes lost in weight. Seven samples of cabbage taken from one large batch of tight, white cabbage heart and cooked on the same day, gave results ranging from $22.4 \%$ loss to $4.2 \%$ gain. All the cooked samples were firm and not overdone and were well drained. Differences in the volume of cooking water may account for some of the differences in the results obtained.

Old potatoes gained or lost as much as $9-10 \%$ on different occasions but the results were irregular. Sloughing caused disintegration of outer layers of Red King potatoes in September $195^{2}$ and broken portions became water-logged before the centre was cooked. This resulted in gain of weight. On other occasions mechanical disintegration of small portions of potato resulted in a loss of weight, presumably because some proportion of the broken part was lost during straining. Provided that rapid boiling and overcooking are avoided it would appear that the variety of potato used is largely responsible for weight changes.

Differences between samples may account for many of the results obtained for one particular vegetable. For example, carrot gained weight only once in 1949. This was in August when only poor-quality vegetables were obtainable, and the gain was probably due to hydration of tissues which appeared comparatively desiccated when raw.

Small whole onions lost less weight than large ones, which may be due to the longer time required to make the large bulb tender, resulting in progressive weight loss throughout the cooking time. It was noticed repeatedly that onions that were almost cooked lost approximately 10\% of their weight and that this loss increased rapidly until cooking was complete. This loss suggests that liberation of cellulose and collapse of cell walls is rapid when the wall structure has become soft.

Pressure cooking. Swedes were cut into slices 0.5 in. thick before cooking and were either boiled in salted water until tender or were cooked at $15 \mathrm{lb}$. pressure (at approximately $116^{\circ}$ ) for $7 \mathrm{~min}$. The mean loss of weight on boiling was $18 \cdot 7 \%$ and on pressure cooking $13.9 \%$, but the range was much wider in pressure cooking, losses of $3 . \mathrm{I}-32 \%$ with one gain of $1 \cdot 4 \%$. The standard error of the mean value for boiling was $1 \cdot 48$ and for pressure cooking $2 \cdot I 6$. There is no satisfactory explanation for the wide range of values for pressure-cooked swede unless the arrangement of slices within the pan influenced weight loss. It is possible that thin slices in the bottom of a pan full of vegetables might be compressed by the weight of those on top, whereas one or two layers spread over a wide area would not be compressed in the same way. Differences in the strength and age of structural cell-wall material probably contributed to weight loss in cooking.

McCance et al. (1936) recorded a weight loss of little more than $5 \%$ when swede was steamed at $120^{\circ}$ for $15 \mathrm{~min}$. It is suggested that the larger loss of weight in the present survey was due to the use of tender vegetables from which a great deal of water was expressed during cooking. 
There was one gain of weight and four losses of less than $6 \%$ in the eighteen samples cooked under pressure. Only two of the fourteen samples boiled in a saucepan lost less than $10 \%$ weight. In view of the fact that gain of weight is said to occur in the first few minutes and that loss of weight is progressively greater with increased cooking, these results are readily explained.

\section{Bread and buns}

Frying. Gain of weight when bread is fried appears to depend on the dryness of the crumb and the nature of the loaf rather than on the amount of fat in the pan or on the length of cooking time. On one day a gain of $3 \mathrm{I} \cdot 4 \%$ was recorded and a surplus of fat remained in the pan, whereas on another a gain of $5 \mathrm{I} \cdot 6 \%$ occurred and all the fat in the pan was absorbed by the bread. McCance et al. (1936) explain that bread gains more fat than it loses water, so that, unlike with potato, weight increases. The differences between the two foods are due to different textures and initial moisture contents.

Toasting. Buns and teacakes lost less weight than bread, which may be attributable to the fact that fat and sugar present in the dough cause rapid browning and reduce the cooking time. There was no apparent difference between the loss of weight when bread was toasted by means of gas, electricity or an open fire.

\section{Cereals}

Differences between individual results for boiled rice and macaroni appeared to depend on the different samples of cereal cooked. The method used throughout was the same and each sample of grain or paste was apparently equally well cooked and drained. In every instance surplus water remained in the pan when cooking was complete.

\section{Dried fruits}

Fruit was well covered with water and left to soak for at least $24 \mathrm{~h}$ or stewed gently until tender. No sugar was added. Prunes gained from $21 \cdot 6$ to $100.0 \%$ in weight after soaking for $24 \mathrm{~h}$ and were all apparently rehydrated and tender.

All dried fruits, especially bananas, varied very considerably in the degree of desiccation. Some prunes were very dry and leathery and others were comparatively juicy. The amount of flesh in proportion to stone also varied (see Table 3).

The maximum increase of weight in one sample of dried banana was $35.8 \%$, whereas a test weighing, made when another sample was still dry and hard in the centre, revealed that weight had increased by $44.0 \%$. Thinly sliced banana gained more weight than did whole bananas soaked until no further gain occurred.

\section{General conclusions}

In view of the many factors contributing to the final weight of cooked foods it is surprising that average results for many foods in this study agree quite closely with those of other investigators. Comparison of loss or gain of weight of meat, fish and vegetables in this study and in earlier experiments shows fairly good agreement and 


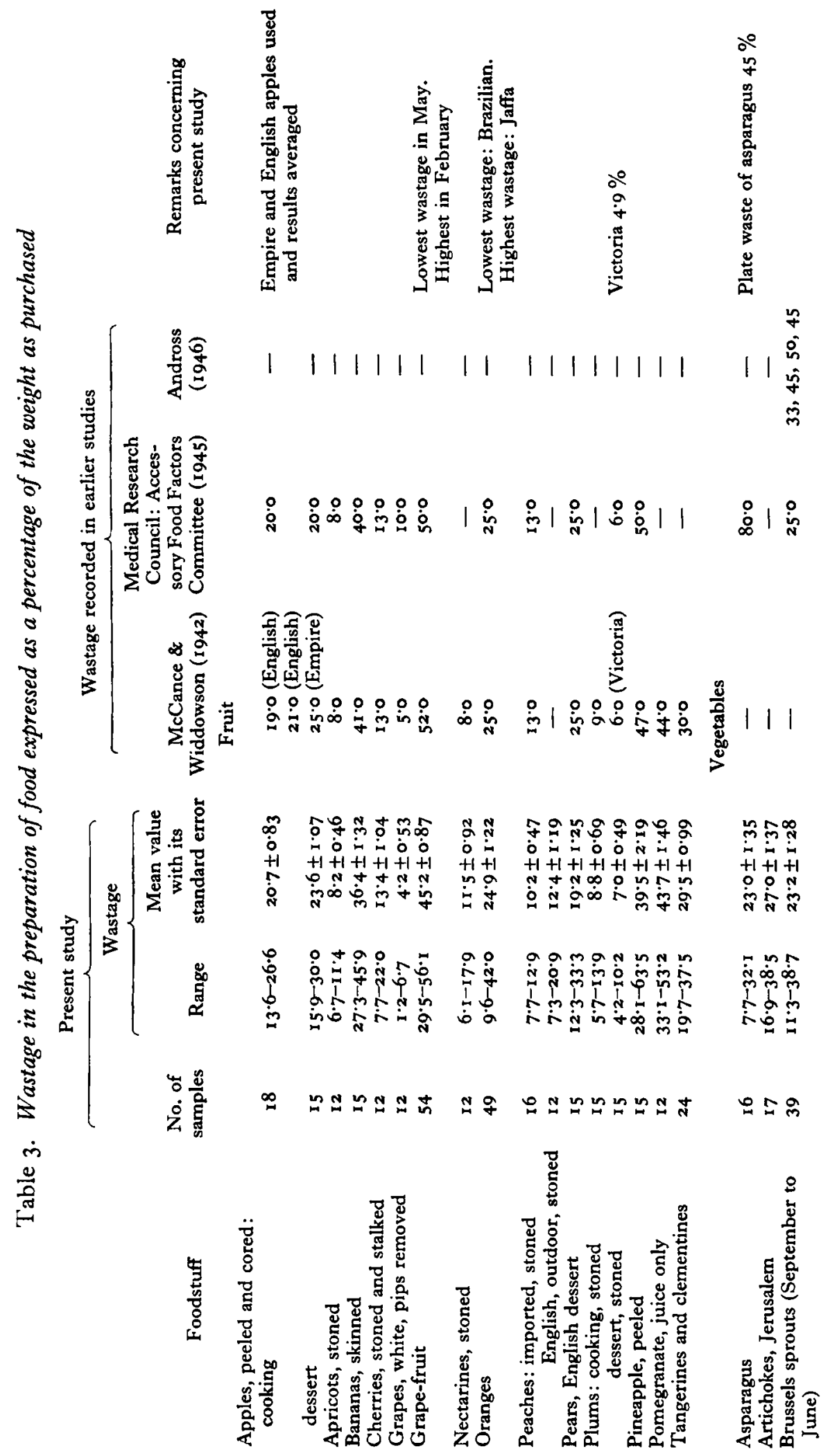



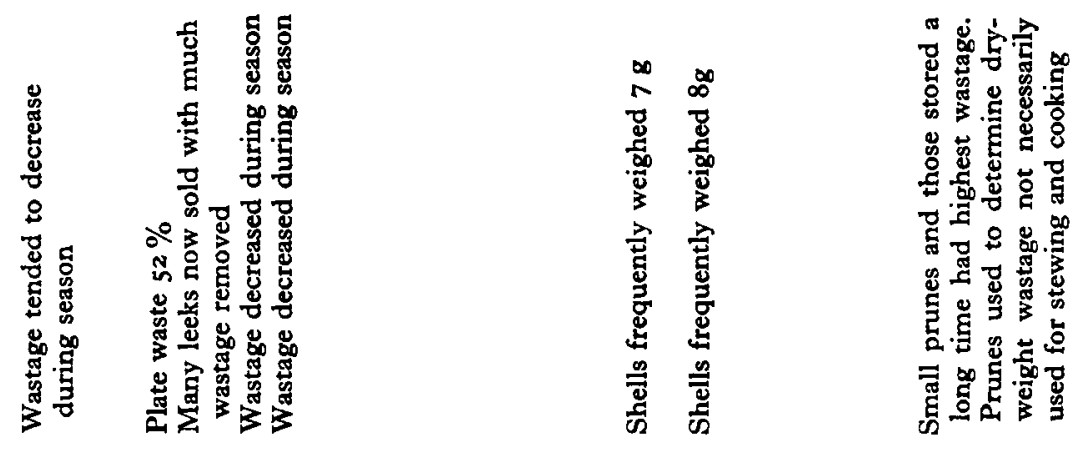

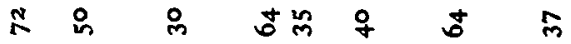

究

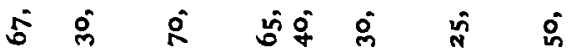

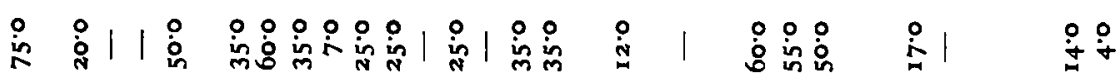

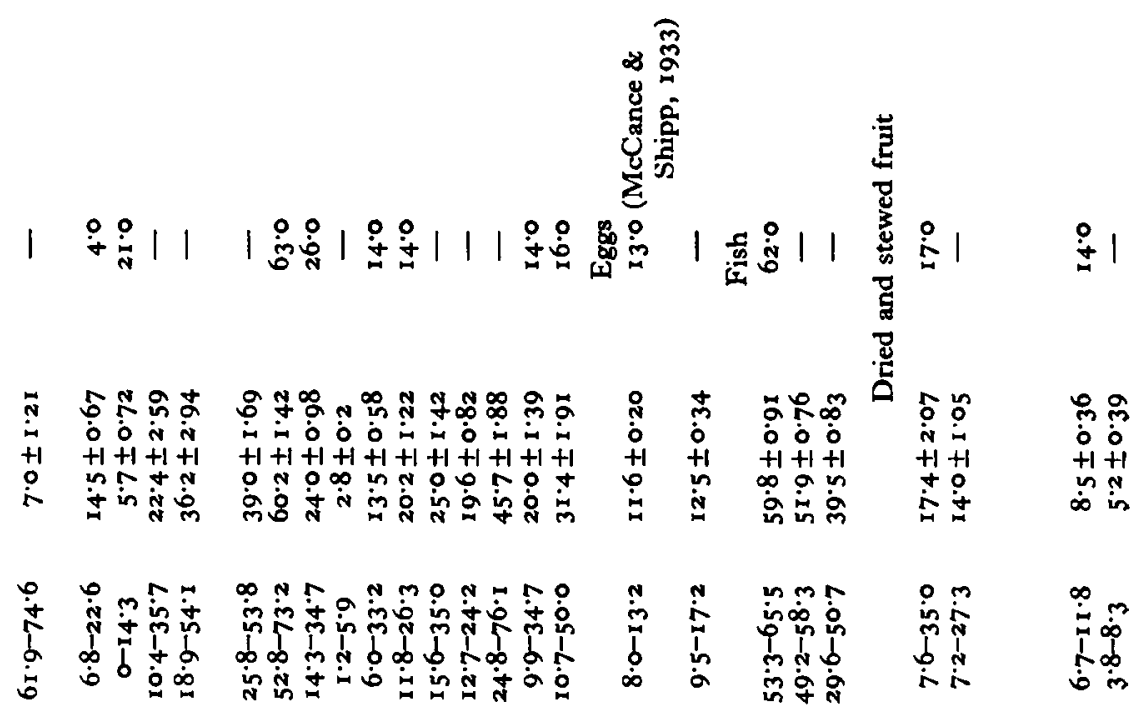

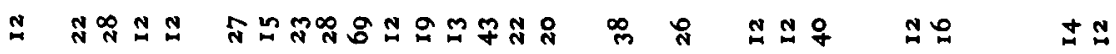

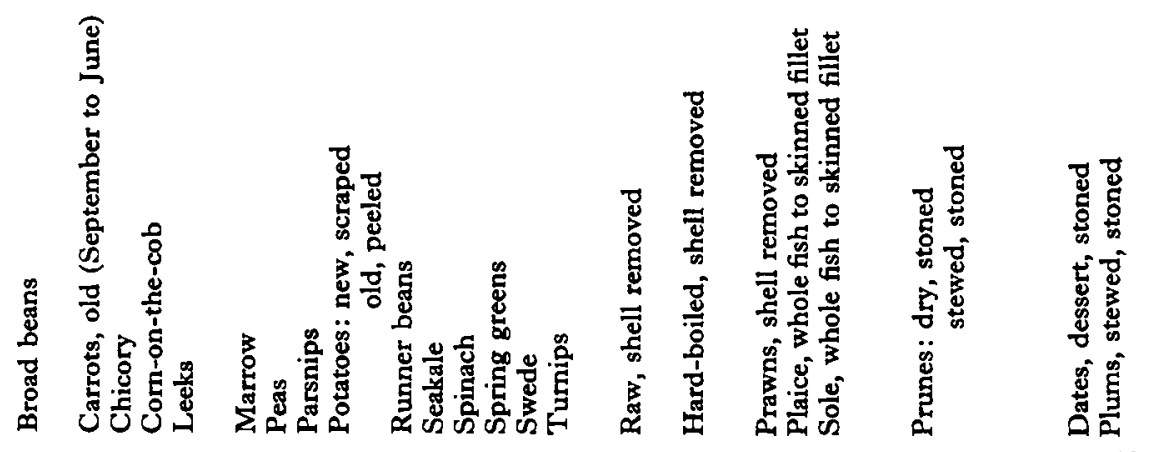


suggests that cooking times and temperatures may be comparable as between investigators. It is probable, therefore, that change of weight of composite cooked dishes would agree equally well with data from other experiments if these were available for comparison.

\section{Wastage}

In Table 3, wastage is expressed as a percentage of the weight of food as purchased. Apart from fluctuations in quality and irrespective of their source, many foods contain inedible portions which must be discarded. Produce sold on the open market varies greatly in quality and the proportion of waste is variable.

Values for wastage in food preparation in this study were obtained with fish, fruits and vegetables purchased between 1949 and 1952 from shops in London and in the country supplying a university college and a private house. Preparation was thought to be careful, so that the percentage of waste recorded in Table 3 should represent the minimum possible for these foods. Where they are available, values for wastage quoted in tables of food consumption are given for comparison with those in the present investigation.

The degree of wastage in the preparation of any one food varies so considerably that it is surprising to find how frequently the mean in this study agrees quite closely with the values given in food tables.

Vegetables. Variation in quality of vegetables offered for sale in different stores and in different districts probably accounts for the $50 \%$ wastage of carrots reported by Andross (1946), $14.5 \%$ in the present study and $4.0 \%$ by McCance \& Widdowson (I942) though the last estimation may have been made on garden produce.

It is unlikely that these large differences were due to differences in method of preparation, since, in all instances, they were carried out by trained investigators.

Values for turnips and swedes showed similar trends.

The most striking difference between earlier values and present ones was in the wastage of raw asparagus. The Medical Research Council: Accessory Food Factors Committee (1945) gives $80 \%$, and the present value was $23 \%$. The lower value must have been due to the use of a different variety of vegetable or to the removal of a larger proportion of waste by retailers.

With several vegetables there was a seasonal variation in wastage. It was especially marked with marrow, peas and broad beans. Early in the season, pea pods represented about $65 \%$ of the total weight as purchased, but as the pods filled this proportion was reduced to about $55 \%$. For broad beans the reduction was from about $70 \%$ to nearer $65 \%$.

The largest losses in the preparation of marrow were found in young vegetables containing a comparatively small proportion of edible flesh to seeds and skin. Typical examples of wastage (mean values) are: sixteen samples of young marrow, $45.3 \%$; eleven samples of old marrow, $30.0 \%$; total for the twenty-seven samples (old and young), $39.0 \%$.

Fruits. Values for fruits were comparatively uniform and there was little evidence of seasonal fluctuation. Grape-fruit gave low values in May (approx. 39\%) when 
Spanish and Italian fruit was on the market. The highest values for wastage were recorded in February (approx. 46\%) when fruit from Israel was on the market.

Average waste from Brazilian oranges was $15 \cdot 1 \%$ and from Jaffa oranges it was as high as $34.8 \%$. Waste due to the removal of stones was remarkably constant for any one variety of plum; for example, Victorias lost $4 \cdot 9 \%(4 \cdot 2-6 \cdot 2 \%)$ and Purple Pershores $6 \cdot 5 \%(5 \cdot 7-7 \cdot 2 \%)$. English peaches grown out of doors generally contained a smaller proportion of flesh to stone than imported peaches.

Fish. The proportion of waste in the preparation of whole plaice and sole is so high that the cost of the edible portion is frequently twice that of the purchased portion.

Analyses of the distribution of waste material were made in January 1952. At this season flat fish have large roes which, although edible, are frequently not eaten.

Table 4. Composition of fish

$\begin{array}{lcc}\text { Plaice } & \begin{array}{c}\text { Sole } \\ \text { (average of } \\ \text { twelve samples) }\end{array} & \begin{array}{c}\text { (average of } \\ \text { forty samples) }\end{array} \\ \text { Fillet } & (\%) & (\%) \\ \text { Roe } & 29.7 & 53.0 \\ \text { Skin } & 20.3 & 7.6 \\ \text { Bone and head } & 9.2 & 10.2 \\ & 40.8 & 29.1\end{array}$

The bone of sole is finer and lighter than that of plaice and the fillet comprises half the total weight of the fish as purchased (Table 4). The amount of waste in plaice is so high that the cost per fillet, sufficient to serve one person, was estimated at Is. $6 d$., $195^{2}$ prices, in the fish weighed for these analyses.

General conclusions. From Table 3 it can be seen that wastage in the preparation of food can be more than $75 \%$ of the purchased portion (spring greens) or as little as $\mathrm{r} \cdot 2 \%$ (new potatoes). Very few mean values in this table were below $10 \%$ and seventeen of the forty-five values recorded reached $25 \%$. If careless or extravagant use of foods in the kitchen is superimposed on essential wastage the cost of edible portions becomes unnecessarily high.

Wastage varies so considerably, for reasons associated with the foods, and with the skill of the cook, that it is difficult to attempt an assessment of the average waste in any community. In view of the rising cost of food in this country any wastage of nutrients is serious from financial as well as from nutritional considerations. Food education is very necessary to prevent the aggravation of an already serious problem, that of too little food for the population of the world.

The World Health Organization (195I) considers 'an essential service in the prevention of malnutrition' to be: 'publicizing the need to prevent wastage of food by applying proper methods of storage and handling of foods' and 'teaching the public how to make the best use of the food available. . by wise planning of home economy. This might include instruction in the economical planning of household budgets and in catering and cooking methods so as to increase palatability, avoid monotony and preserve nutritional value.' 
SUMMARY

1. A table of the change of weight of various foods during domestic cooking is presented. Loss of weight varied between 13 and $37 \%$ for puff pastry, 7 and $33 \%$ for grilled fish and 13 and $39 \%$ for roast meats. Green leafy vegetables generally gained weight on boiling.

2. A list of the wastage of fruits, vegetables and fish during preparation for the table is given and average values are compared with those in tables of food composition. Unavoidable waste is so great for many commodities that persons handling foods should avoid wastage due to careless preparation.

\title{
REFERENCES
}

Andross, M. (1940). Chem. \& Ind. 59, 449.

Andross, M. (1941). Chem. \& Ind. 60, 176.

Andross, M. (1946). Proc. Nutr. Soc. 4, 155.

Lowe, B. (1944). Experimental Cookery, 3rd ed., p. 25r. London: Chapman and Hall.

McCance, R. A. \& Shipp, H. L. (r933). Spec. Rep. Ser. med. Res. Coun., Lond., no. 187.

McCance, R. A. \& Widdowson, E. M. (1942). Spec. Rep. Ser. med. Res. Coun., Lond., no. 235.

McCance, R. A., Widdowson, E. M. \& Shackleton, L. R. B. (1936). Spec. Rep. Ser. med. Res. Coun., Lond., no. 213.

Medical Research Council: Accessory Food Factors Committee (1945). M.R.C. (War) Memor. no. 14. Simpson, J. I. \& Halliday, E. G. (1941). Food Res. 6, 189.

World Health Organization (195I). Tech. Rep. Wld Hlth Org. no. 45, p. 15.

\section{The Microbiological Assay of 'Vitamin $B_{12}$ ' in the Milk of Different Animal Species*}

\author{
BY MARGARET E. GREGORY \\ National Institute for Research in Dairying, University of Reading \\ (Received 2 April 1954)
}

Values for the 'vitamin $B_{12}$ ' content of the milk of different species of animal have been published by Collins, Harper, Schreiber \& Elvehjem (I95I), who used Lactobacillus leichmannii ATCC 4797 as the assay organism, and by Sreenivasamurthy, Nambudripad \& Iya (1950), who used Lactobacillus lactis Dorner. Both groups of workers made their determinations on diluted whole milk. Results obtained at this Institute have shown that for some milks a preliminary treatment was necessary before the 'vitamin $\mathrm{B}_{12}$ ' was fully available to the assay organism (Gregory, Ford \& Kon, 1952).

The assay organisms used by Collins et al. (1951) and Sreenivasamurthy et al. (1950) are not specific for cyanocobalamin (vitamin $\mathrm{B}_{12}$ ). Thus Lb. leichmannii responds to.factor $A$, pseudovitamin $B_{12}$ and deoxyribosides besides cyanocobalamin (Ford, I953a), and deoxyribosides can replace cyanocobalamin as a growth factor for Lb. lactis (Shive, Ravel \& Harding, 1948). For this reason, the term 'vitamin $\mathrm{B}_{12}$ ' is

\footnotetext{
- This investigation forms part of a thesis for the degree of Ph.D. in the University of Reading.
} 